vice as had never hefore been scen, contributed numberless essays on disease and wounds, and passed again into private life the unremembered, unrewarded servants of duty. How far it taxed the average professional man of the cities-your city and minemay be judged from the fact that in 1864 the living Fellows of the College of Physicians of Philadelphia were 174. Of these, 130 had been connected in one way or another with the service of the army or navy during the four years of that bloody struggle-certainly a record of honor. What has been our reward? The great leaders in war have been promoted and universally honored. Countless statues commemorate in Washington and elsewhere the popular heroes. Statues of generals are in every town, some of them memorials of men it were wiser to forget, some of whom history will judge severely. Every village has its statue to the private soldier. There is not a state or national monument to a surgeon. At Gettysburg, every battery site is marked with a recording tablet; every general who fell, Union or Confederate, is remembered in bronze or marble; but what of the surgeon who died? Nothing!

It is a relief to know that I have of late induced the Gettysburg Commission to mark with a bronze shield the site of every corps hospital, with the names of the surgeons who served in each. Please to fully realize the fact that this will be absolutely the first national recognition of the physician in the war. The situations of the Confederate division hospitals have also been marked. You will share with me the pride and pleasure all this has given me.

Has any one ever heard of the medal of valor being given to a physician? And what of the young surgeons who volunteered to test the fever-bearing bite of the mosquito-more deadly than the fang of the rattlesnake! Shall we be proud that the Republic asks of us, expects from us, every service, and has for us no honoring recognition in life and no memorial marble for those of us who died on the field of honor?

What, indeed, shall we ask for the surgeon who on the Isthmus of Panama made possible that gigantic piece of engineering surgery which, cleaving a continent in twain, made of it two vast islands and wedded sea to sea?

Ah, when I think of the risks some of us have taken, the laboratory problems to be solved at daily personal peril. I am proud of the silence of our courage. Contrast with the thunder of the reputations made in our tiny Spanish War the tranquil, modest efficiency of that more deadly war which Reed and his officers conducted against yellow fever. I conclude that perhaps after all our way is the better. We wage no kindergarten wars!

Let me close with what very long ago I said in forgotten verse far better than I can say it in prose. I wrote of the Goddess of Medicine:

Fair heritress of every human hope.

Rich with the marvels of time's widening scope,

However high may rise thy soaring wing,

Whatever change thy fuller days may bring,

Our ancient lesson will be ever new;

That priceless lesson will be ever true;

Time did not teach it; time will change it not;

This, this shall last though all our lore's forgot,

To give what none can measure, none can weigh,

Simply to go where honor points the way;

To face unquestioning the fever's breath,

The hundred shadows of the vale of death;
To bear Christ's message through the battle's rage,

The yellow plague, the leper's island cage,

And with our noblest "well to understand

The poor man's call as only God's command."

Ay, under every century's changing sky,

Shall the Greek master's triple signal fly-

Faith, honor, duty-duty calmly done,

That shouts no self-praise o'er a victory won;

One bugle note our oniy battle call,

One single watchword, Duty-That is all.

\section{PALLIATIVE EFFECT OF ARTIFICIAL PNEUMOTHORAX IN TREATMENT OF PULMONARY TUBERCULOSIS *}

WILLIAM C. VOORSANGER, M.D.

Visiting Physician, Mt. Zion Hospital; Clinician, San Francisco Tuberculosis Clinic; Medical Director, Oaks Sanatorium, Los Gatos

SAN FRANCISCO

Artificial pneumothorax or lung compression has assumed its place as an important factor in pulmonary therapy. Murriston Davies designates it as the greatest present-day advance in lung surgery. Phthisiotherapists, with a few ultraconservative exceptions, are beginning to look on it as the greatest addition to their armamentarium since Koch's discovery of tuberculin. So important has it become that several articles have appeared during the past three years as to who should be given priority for its discovery.

Forlanini, in a comprehensive monograph, ${ }^{1}$ states that Carson (an English physician) in 1843, himself in 1881, and Murphy in 1898, each independently of the other's work, gave birth to the idea of placing a badly diseased lung at rest by compression with gas. Forlanini, as far as I can ascertain from a scrutiny of the literature on the subject, must be credited with the idea of performing artificial pneumothorax "medically" instead of surgically. Forlanini did not perform the operation until several years after his utterances of 1881 .

Following the lead of Forlanini, the Germans seized eagerly on this method, and to Brauer and Spengler ${ }^{2}$ belong the credit of stimulating world-wide interest by their celebrated report of 102 cases, representing operations performed at Davos, Switzerland, and in Hamburg, Germany, over a period of five years. They, however, changed Forlanini's method by creating the Schnitt Methode (incision method). They make a fairly large incision over the fourth, fifth or sixth intercostal spaces anteriorly, expose the intercostal muscle, and then force a blunt Salomon cannula into the pleural space. Brauer firmly maintains that his method is the only correct one, since it insures safety to the patient and absolute knowledge of the presence of the cannula in the pleural cavity. Still, Forlanini's method has become the one of choice among the majority who perform this operation (even the Germans), because it is far simpler and does not submit the patient to a surgical operation of considerable severity, and with improved technic and the more careful observation of the manometer, the accidents, particularly those occasioned by gas emboli, which occurred occasionally in the earlier operations, are to-day practically eliminated. Therefore, barring the cases of extensive pleural adhesions, the Forlanini, or

* Read before the St. Francis Medical Society, March 27, 1914.

1. Forlanini: Therap. d. Gegenw., 1910, Nos. 5 and 6.11 , xix, 1. 
puncture method, is applicable to all cases in which artificial pneumothorax is indicated, and the Brauer, or incision method, should be reserved for the former.

From the numerous reports pouring in, and from my own limited experiences in the past two years, I feel confident that Brauer's method will in future be very rarely employed.

Just exactly what are we trying to accomplish when we compress a tuberculous lung? Principally delay; time in which to allow our other methods of treatment to become efficacious. Rest is given the tuberculous patient to prevent auto-inoculation. What more rational than rest, direct and complete rest, to the diseased part which is generating toxins? Forlanini states that an artificial pneumothorax must place the lung at "atsolute rest, and this must be maintained until absolute cure results."

The direct effect of compressing a diseased lung with nitrogen is sometimes most startling. I have seen a stubborn cough cease within twenty-four hours after complete compression; temperature drop to normal after a few days; sputum rapidly diminish, and a general all-round improvement result in the patient's condition. There can be no question that artificial pneumothorax has rescued many tuberculous patients who did not respond to other methods of treatment and who would have died otherwise.

The theories of the mechanism of healing by this treatment as generally agreed on are: (1) rest to the involved organ; (2) an ischemia of the lung because of the elimination of venous circulation; (3) a diminution of toxin absorption, and (4) ultimate scarring over of diseased tissue. Perhaps more theories will evolve to explain further why we sometimes obtain such remarkable results in hopeless cases, when all other methods have proved futile. The direct effect of nitrogen on the tissues may offer a fertile field for investigation.

The indications for performing an artificial pneumothorax have been concisely given by $\mathrm{Zink}^{3}$ in a report of 110 cases in which operation was performed at the Basel Sanatorium, Davos, as follows: (1) in all chronic destructive tuberculous processes (limited to one lobe) with a tendency to fibrous degeneration and cavity formation; (2) in all severe acute infiltrating and cheesy pneumonic forms; (3) in chronic infiltrating lesions without much destruction if they are of a progressive character or show no tendency to retrogression under prolonged treatment by other means, and (4) in uncontrollable hemorrhage. These indications are an amplification of those originally laid down by Forlanini and Brauer and Spengler.

The original warning not to compress a diseased lung when the other was involved has been modified. Reports of 104 cases, by Saugman, involving 5,000 inflations, Zink's exhaustive treatise, the recent further report of eighty-eight cases by Lucius Spengler, and the recent work of Dunham and Rockhill ${ }^{4}$ in this country prove that in bilateral cases in which there is not too much involvement of the "good" lung, the other may be successfully and safely compressed. Arsperger ${ }^{5}$ also reports excellent results in pleurisy with effusion, by early aspiration of the effusion, and introducing between the sheets of the pleura from 150

3. Zink: Beitr. z. Klin. d. Tuberc., 1913, xxviii, 155.

4. Dunham, Kennon, and Rockhill, Charles S.: Therapeutic Pneumothorax as a Palliative Measure, Safeguarded by Stereoroentgenograms, a Report of Twenty Cases, The Journal A. M. A., Sept. 13, 1913, p. 826 .

5. Arsperger: Beitr. z. Klin. d. Tuberc., 1913, xxviii. to 600 c.c. of nitrogen to keep them apart and check further production of effusion and adhesions. Incidentally he combines this method with autoserotherapy, that is, the subcutaneous reinjection of from 1 to 3 c.c. of the patient's own effusion.

Claude Lillingston, Herbert Rhodes, Robinson and Floyd, Rist, Maingot, Barnard in France, Sauerbruch and von Muralt, and numerous others who have given more or less extensive reports of their work during the past three years, agree on these indications. Mary Lapham $^{6}$ states as contra-indication (to lung compression), "any complication sufficient in itself to inhibit recovery and too great an involvement of the other lung." In short, in the reports of more than a thousand cases; representing many thousand inflations reported during the past five years by the best observers and workers in the field of pulmonary tuberculosis, there seems to be an agreement that artificial pneumothorax should be performed only when one lung at least is fairly sound; that it should be reserved for the case which does not respond to other therapy, and that it should be used only in cases in which, through its application, there will be a chance of arresting the disease.

In my own work during the past two years it occurred to me that in hopeless cases the patient who was constantly coughing and expectorating without relief might, through this method, end his days in comfort without the use of the large doses of morphin. I therefore attempted lung compression in three cases of very advanced tuberculosis with severe involvement of both lungs, in which, however, a large cavity could be diagnosed in one. These patients all had violent, persistent coughs and excessive purulent expectoration, the picture usually seen in terminal tuberculosis. They were selected because in each case a large cavity could be diagnosed in one lung, and on the rather dangerous assumption that the cough and expectoration was being formed in this cavity. At any rate, it seemed right to test the palliative effect of lung compression. The patient in each case was warned of the danger of the procedure and his consent and that of responsible relatives obtained. The report of these cases is briefly given below.

CASE 1.-F. O., army lieutenant, aged 34, seen at Letterman Hospital, Presidio, May 15, 1913, had had repeated attacks of high temperature for two years which had been diagnosed as malaria. Bacilli of tuberculosis had been found in sputum six months ago. The patient returned from the Philippines three weeks ago and had been in bed ever since. $\mathrm{He}$ had lost 40 pounds in six moriths, and was a much-emaciated man. The temperature ranged from 98 to 103 . Examination of lungs showed extensive involvement of both lungs, most pronounced in the left, with a large cavity in the lower lobe of the left lung. The sputum measured from 8 to 10 ounces daily and showed numerous bacilli. Cough was persistent. The condition of the patient was very bad and the prognosis had been given of "exitus in about two weeks." The patient was removed at considerable risk to a private sanatorium, and on May 25 the first pneumothorax was performed, 100 c.c. nitrogen being admitted through the seventh intercostal space in the midaxillary line, under novocain ( 0.5 per cent.) anesthesia. The effect on the patient of even this small amount of gas was most distressing. He became quite cyanotic and was very dyspneic for about two hours. May 30, 200 c.c. nitrogen were admitted; June 7, 250 c.c.; June 14, 700 c.c., and June 28,850 c.c. Subsequent inflations after the first were fairly well tolerated, and after the second the temperature became lower and the sputum started to decrease. After the fourth

6. Lapham, Mary E.: The Treatment of Pulmonary Tuberculosis, ThE JOURNAL A. M. A., Sept. 14, 1912, p. 866 
inflation, June 14, 1913, the patient's cough had practically disappeared, the sputum never reached more than $5 / 2$ ounce in twenty-four hours, his weight had increased about 10 pounds, and in all respects he was greatly improved. June 29 , after his fifth inflation, he left the sanatorium and went to Fort Bayard, N. Mex. It had been his great desire to go to the latter place, but his weakness prior to pneumothorax treatment had been so intense that the removal was interdicted. He made the two days' trip without mishap. Advices from Fort Bayard, September 26, showed that he had received two further inflations and was improving. His improvement continued until very recently, when he became rapidly worse and died March 7, 1914.

I feel certain that lung compression in this case prolonged the patient's life for nearly ten months, most of it in comfort.

CASE 2.-P. V., referred by Dr. John Gallwey, with a very advanced, hopeless case of tuberculosis of five years' duration, was a much-emaciated man, with extensive infiltrations of both lungs, with a large cavity in the middle lobe of the right lung. The cough was contant and painful, and the dyspnea at times most distressing. Sept. 20, 1913, 100 c.c. nitrogen were admitted into the seventh interspace, right midaxillary line. September 22,400 c.c. nitrogen were admitted. After this inflation the patient became very cyanotic and dyspneic. September 23, the patient left the sanatorium and went to his home feeling better. For one month after this the patient, although there was no change in his general condition, almost entirely lost his cough. He died about six weeks after the second inflation.

CASE 3.-G. S., first seen Aug. 5, 1913, had a history of slight cough, and a loss of 5 pounds in weight. One brother and several relatives on both the father's and mother's side of the family died of tuberculosis. There was a slight lesion in the apex of the right lung. No bacilli were found in the sputum. Von Pirquet was positive. Dietary treatment, rest and tuberculin were resorted to and the patient improved rapidly, gaining twelve pounds in weight and entirely losing the congh. November 28 , he appeared at my office very much frightened, as he was having an extensive hemoptysis. $\mathrm{He}$ was immediately put to bed and kept quiet until the hemorrhage had partly ceased. November 29 , the sputum, which had been free from tubercle bacilli, showed large numbers of the latter. December 5th, the hemoptyses had stopped but the temperature ranged from 100 to 104 , and examination revealed an extensive cavity in the middle lobe of the right lung and beginning infiltration of the left lung. This condition can be accounted for only on the theory that the right lung must have been centrally undermined so that no physical signs were apparent. A sudden rupture into a large vessel caused the hemorrhage and opened up the cavity. The patient's condition becoming rapidly worse, pneumothorax was applied December 17 (Forlanini method), by admitting 350 c.c. of nitrogen into the sixth interspace right midaxillary line. December 18,400 c.c. were admitted. December 27,800 c.c., and January $17,1,000$ c.c. The patient's cough became greatly improved, "blood-spitting" following the hemoptyses ceased, and the temperature dropped to 99.5 . February 1 , he was suddenly seized with pneumonia, and died Feb. 4, 1914.

This was undoubtedly an acute, progressive tuberculosis, and the prognosis was in doubt from the start.

These three cases, all different in type but progressive, advanced and hopeless, were selected for lung compression to relieve cough and expectoration and not with a hope of arrest. In the former sense, the procedure must be looked on as successful.

I should, therefore, like to add to the indications usually given for lung compression the following: Hopelessly advanced cases in which after careful examination it is ascertained that cough and expectoration is being produced from a large cavity in one lung even though the other is badly infiltrated.
The technic of artificial pneumothorax is simple. I use a Hawsmann modification of the Forlanini apparatus and a trocar 2 inches in length. I formerly used a larger trocar of wider caliber, but have found the shorter one more satisfactory in most cases, as with it there is little danger of penetrating the lung. Great care should be exercised in avoiding damage to the lung-tissue. As careful a sepsis should be used as in any operation. I use as an anesthetic 0.5 per cent. novocain, and apply it first deeply and then superficially. In this way I believe that the so-called eclamptic attacks due to a pleural reflex, and cases of nervous shock can be, to a great degree, avoided.

Much has been written recently by Sillig ${ }^{7}$ and Orlowski and Jofanno ${ }^{8}$ on pleural reflexes, which are now believed to be responsible for such conditions as laryngospasm, slowing of the pulse, vertigo, cough, sudden paleness of the face and fainting. These conditions heretofore have been attributed to gas emboli.

I always use the Forlanini method and pass the trocar in the sixth or seventh interspace in the midaxillary line whenever possible. Careful physical examination controlled by roentgenography should guide the operator as to the best space for entrance. When adhesions prevent going into the space of choice, an attempt may be made higher up in the fifth or fourth interspace anteriorly. Several punctures are sometimes necessary before arriving in a free pleural
space.

The real success in applying artificial pneumothorax lies with the manometer. One is sure that he is in the pleural cavity by the manometer registering negative pressure. The manometer tells us, by not registering at all or by registering positive pressure, whether we are in lung tissue, in a blood-vessel, in the pleural wall, or whether our needle is obstructed. Brauer calls negative pressure a pneumothorax symptom. Sometimes when no fluctuation of the manometer is obtained, a small amount of nitrogen-from 25 to 50 c.c.- may be cautiously admitted. If small adhesions are present, these will be broken and the manometer will then register.

Considerable has been written on the reading of the manometer. The number of millimeters negative or positive pressure is immaterial. The rule which I have established for myself is never to allow gas to flow until the manometer registers free and full fluctuations, and immediately to stop the flow when the pressure changes from negative to positive. I do not measure the exact amount of the latter, because I never on first inflation allow more than from 300 to 400 c.c. to enter, and sometimes stop with 100 . On the following day from 300 to 500 c.c. are given, then an interval of two or three weeks is.allowed to elapse, when from 600 to 800 c.c. are admitted, depending on the manometer. After the third inflation, compression is performed every few weeks and sufficient nitrogen admitted to maintain positive pressure, not to exceed 1,000 c.c.

Robinson and Floyd in this country give 1,000 c.c. as first injection. Originally Forlanini, Brauer and their disciples gave as high as 2,000 c.c. at an inflation, obtaining the highest possible positive pressure. Subsequent observers have shown this to be not only unnecessary but absolutely dangerous, causing such complications as emphysema, dislocation of the heart

7. Sillig: Rev. médicale de la Suisse romande, 1913, No. 7, excerpt 8. Orlowski and Jofanno: Beitr. z. Klin. d. Tuberc., 1914, xxx, No. 1. 
and rupture into the opposite lung. The best results to-day are accomplished by using just enough nitrogen to compress the lung sufficiently. This never should on first inflation exceed 400 c.c., and on subsequent inflations 1,000 c.c. Pressure should be tested after admission of each hundred cubic centimeters. If these precautions are taken, the numerous complications heretofore reported may be avoided. In my own work the only complication (in two cases) has been a subcutaneous emphysema which, although slightly painful, disappears in a few days.

The results in artificial pneumothorax have been uniformly good. Brauer and Spengler ${ }^{2}$ in their 102 cases assert that accurate statistics of arrests by this method are not practicable, since (1) every case must be analyzed for itself; (2) in many cases we fail to produce a pneumothorax on account of pleuritic adhesions, and (3) cases in which we expect failure are often successful and vice versa. They conclude, however, by stating that they obtained results which could not have otherwise been accomplished.

Saugman ${ }^{9}$ reported 104 cases. In 30 per cent., pneumothorax could not be performed. In seventy-two cases, effectual compression was obtained. He reports good results.

$\mathrm{Zink}^{3}$ in 110 cases, reports that he accomplished effectual compression in eighty-one cases.

Lucius Spengler ${ }^{10}$ reports eighty-eight cases, in which he obtained in twenty-three cases, or 26 per cent., permanent results in from six months to five years. Thirty-six patients, or 41 per cent., are under treatment but improving; ten cases, or $111 / 3$ per cent., are improved, and nineteen cases, or $212 / 3$ per cent., were unsuccessful. He reports a favorable result in $78^{\mathrm{I} / 3}$ per cent. of all cases.

E. Grundt ${ }^{11}$ reports twenty-eight cases, with success in nine.

L. Hamman and M. F. Sloan ${ }^{12}$ report twenty cases with successful results.

Rothschild and Fehleisen ${ }^{13}$ report thirty-three cases with good results.

R. C. Matson ${ }^{14}$ reported sixteen cases with three arrests and five cases steadily improving.

Dunham and Rockhill ${ }^{4}$ treated twenty patients with good results. They dwell particularly on the value of Roentgen examinations.

H. M. King and C. W. Mills ${ }^{15}$ report sixteen cases. In two cases there was permanent arrest, in six temporary improvement, and in one case hemorrhage (which was controlled).'

In six cases on account of pletral adhesions compression was unsuccessful.

Mary Lapham ${ }^{6}$ reports thirty-one cases with success in 40 per cent.

My own cases thus far number fourteen, covering a period of less than two years. The cases have been carefully selected from a large material, based on the indications as given above. The number is small because I am still of the belief that only those cases should be reserved for artificial pneumothorax which, after a fair test, do not respond to our other welltried methods of treatment. In this series are those

9. Saugman: Internat. Cong. Med., London, August, 1913 10. Spengler, Lucius: Internat. Centralbl,, January, 1914.

11. Grundt, E.: Med. Rév., 1913, No. 6.

12. Hamman, L., and Sloan, M. F.: Johns Hopkins Hosp. Bull., Feb.

ruary, 1913.
13. Rothschild and Fehleisen: California State Med. Jour., September, 1913.

14. Matson, Ralph C.: Northwest Med., January, 1914, p. 10 331 . advanced cases reported above. Of the other eleven, two patients could not be inflated, one on account of adhesions, the other on account of an old pleurisy with effusion. Three cases are arrested, one patient is rapidly improving, and four patients are progressing favorably, being inflated at intervals of four weeks. Two patients stopped treatment of their own volition. All cases were, whenever possible, controlled by roentgenograms before operation and before the second inflation. All compressions have been made by the Forlanini method, with 0.5 per cent. novocain anesthesia.

I cannot agree with those observers who assert that artificial pneumothorax should be performed only in a hospital or sanatorium. I have performed it at the clinic, at my office and at the patient's home. Whenever possible I perform the first inflation at a hospital, permitting the patient to leave the same day. When a pneumothorax is once established, subsequent inflations are simply and quickly performed if one's technic is correct. I agree with Lillingston ${ }^{16}$ who states that most cases of sudden death in the past have been due to faulty technic. As long as careful asepsis, careful anesthesia and careful reading of the manometer are observed, no accidents of serious import should occur.

I wish to thank Dr. George H. Hubbell for the valuable assistance rendered in the roentgenographic work in these cases.

162 Post Street.

\section{RADIUM TREATMENT OF CUTANEOUS EPITHELIOMAS BY SINGLE OR MASSIVE DOSES *}

\section{A. SCHUYLER CLARK, M.D. NEW Y $3 R K$}

Wickham and Degrais ${ }^{1}$ have microscopically determined that "cancer cells, exposed to radium after a primary hypertrophy, disorganize, become soft, disintegrate and are probably eliminated by a phagocy tosis. The connective tissue enveloping and separating the mass of cancer-cells, on the other hand, is stimulated and regenerated by the invasion of embryonic nuclei, which dissociate the groups of cancerous cells, finally replacing them. These modifications tend to a fibrous transformation of the tumor, producing, as we know, the unusually good scar that results with such a healing." That any one of the three so-called alpha, beta or gamma rays has an advantage in producing this effect I cannot affirm. I should rather believe that in the method I use the results are probably due to the great amount of rays to which the tissues are exposed, for I use no screen except a thin layer of mica which only filters out some of the alpha rays. The gamma rays constitute only 1 per cent. of the whole radio-activity and, while they are the ultrapenetrating rays and the only ones available for treating deep-seated lesions through the unbroken skin, they are in such a comparatively small quantity that most extensive exposures would seem to be necessary to get a sufficient effect. This in a measure can be overcome by the multiple source and cross-fire methods

\footnotetext{
16. Lillingston, Claude: Lancet, London, 1913, ii, 185.

* Read before the United Medical Society of New York.

1. Wickham and Degrais: Radiumtherapy, Funk and Wagnalls Co., New York, 1910.
} 